\title{
Clinicopathological characteristics of BRCA-associated breast cancer in Asian patients
}

\author{
Eun-Kyu Kim¹, So Yeon Park ${ }^{2}$, Sung-Won Kim ${ }^{3}$ \\ Departments of ${ }^{1}$ Surgery and ${ }^{2}$ Pathology, Seoul National University Bundang Hospital, Seoul National University College of Medicine, Seongnam; \\ ${ }^{3}$ Department of Surgery, Daerim St. Mary's Hospital, Seoul, Korea
}

$B R C A 1 / 2$ germline mutations account for the majority of hereditary breast cancers. Since the identification of the $B R C A$ genes, several attempts have been made to define the clinicopathological characteristics of BRCA-associated breast cancer in comparison with sporadic breast cancer. Asians constitute $60 \%$ of the world population, and although the incidence of breast cancer in Asia remains low compared to the West, breast cancer is the most prevalent female cancer in the region. The epidemiological aspects of breast cancer are different between Asians and Caucasians. Asian patients present with breast cancer at a younger age than Western patients. The contributions of BRCA1/2 mutations to breast cancer incidence are expected to differ between Asians and Caucasians, and the different genetic backgrounds among races are likely to influence the breast cancer phenotypes. However, most large-scale studies on the clinicopathological characteristics of BRCA-associated breast cancer have been on Western patients, while studies on Asian populations were small and sporadic. In this review, we provide an overview of the clinical and pathological characteristics of $B R C A$-associated breast cancer, incorporating findings on Asian patients.

Key Words: Breast neoplasms; Genes, BRCA1; Genes, BRCA2; Asian Continental Ancestry Group

Received: March 23, 2020 Accepted: April 7, 2020

Corresponding Author: Sung-Won Kim, MD, PhD, Department of Surgery, Daerim St. Mary's Hospital, 657 Siheung-daero, Yeongdeungpo-gu, Seoul 07442, Korea

Tel: +82-2-829-9515, Fax: +82-2-833-6224, E-mail: brcakorea@gmail.com

Breast cancer is the most frequent female cancer that remains the leading cause of cancer death in women globally, which amounted to $25 \%$ (1.7 million) of all new cancers and $15 \%$ $(521,900)$ of all cancer deaths in year 2012 [1]. Genetic predisposition is one of the major risk factors in breast cancer which constitutes $5 \%-10 \%$ of all breast cancers [2]. About 20\%-40\% of inherited breast cancers are attributed to deleterious mutations in the breast cancer-associated genes BRCA1 and BRCA2 [3]. Women who have $B R C A$ germline mutations are at an increased risk of developing breast and ovarian cancers [4]. Meta-analyses indicate that BRCA1 and BRCA2 carriers have a 57\%-65\% and $45 \%-49 \%$ probability of developing breast cancer over lifetime, respectively $[5,6]$. BRCA1/2 germline mutations are more common in patients with a family history of breast or ovarian cancer, personal history of breast cancer at young age, or triple-negative phenotype (for BRCA1 only) [7-9]. The prevalence of these genetic mutations varies among ethnic groups and countries. However, most studies of hereditary breast cancer have been on Caucasians in Europe and North America.

Asians make up $60 \%$ of the world population. Although the incidence is low compared with Western countries [10], breast cancer is the most prevalent female cancer in Asia, and its incidence is continuously increasing [11-14]. Asian patients develop breast cancer at younger age than their Caucasian counterparts $[13,15]$. Thus, the contributions of BRCA1/2 germline mutations to breast cancer incidence are expected to differ between Asians and Caucasians. In addition to the age of onset, epidemiological aspects of breast cancer are quite different between patients in Asia and those in the West. The different racial background leads to different genetic backgrounds, which in turn, may result in different breast cancer phenotypes.

The reported prevalence of BRCA1/2 germline mutations in Asian patients with familial breast cancer ranges from $8.0 \%$ to $31.8 \%$ and in those with early-onset breast cancers from $2.8 \%$ to $21.4 \%$ [13]. The prevalence of BRCA1/2 mutations in familial breast cancer in Asians is similar to that of African and His- 
panic Americans but lower than Ashkenazi-Jews and North Americans of Caucasian descent. The prevalence of BRCA1/2 mutations in early-onset breast cancer in Asians is similar to that of Caucasians and African Americans. It has been reported that $B R C A 2$ mutations have a higher incidence in Asians with the exception of Indians and Pakistanis, whereas BRCA1 mutations are more prominent in other ethnicities $[13,16]$. In a recent study from a Chinese cohort, BRCA mutations were identified in $9.1 \%$ of cases with at least one risk factor for hereditary breast cancer, $3.5 \%$ of sporadic patients, and $0.38 \%$ of healthy controls [17]. In Western countries, the estimated cumulative risk of breast cancer to the age of 70 years in BRCA1 and BRCA2 mutation carriers ranges from $72 \%-87 \%$ and $71 \%-84 \%$, respectively [4,18-20]. The estimated cumulative risk of breast cancer to the age of 70 years is $72.1 \%-66.3 \%$ and $78 \%-80 \%$ for BRCA1 and $B R C A 2$ mutation carriers in Korea and Japan, respectively [21,22].

Current treatment recommendations for BRCA-associated breast cancer are similar to sporadic breast cancers, which mainly include surgery, radiotherapy, and chemotherapy. However, as chemotherapeutic regimens are becoming increasingly tumor-specific, it is possible that patients with BRCA mutations will be treated differently in the future. Recently, for example, various clinical trials have investigated polyadenosine diphosphate-ribose polymerase (PARP) inhibitor treatment for advanced breast cancer patients with germline BRCA1/2 mutation. Among the various PARP inhibitors, olaparib and talazoparib, which reached phase III clinical trials, showed a significant benefit over standard chemotherapy with respect to progression-free survival $[23,24]$. Thus, it is important to determine the clinical characteristics and tumor pathological features of $B R C A$-associated cancers that may affect treatment recommendations.

Most studies on Asian patients have focused on the incidence and prevalence of $B R C A$ mutation in high-risk women and their families [13,25-28], and few studies have investigated the clinicopathological features of BRCA-associated breast cancer $[17,26,29,30]$. In this review article, we review the literature, including Asian studies, on clinical and pathological characteristics of BRCA-associated breast cancers.

\section{CLINICAL CHARACTERISTICS OF BRCA1/2-ASSOCIATED BREAST CANCER}

As opposed to sporadic breast cancers, breast cancers with mutations in high-penetrance susceptibility genes display distinctive clinical features: younger age at diagnosis, higher inci- dence of bilateral breast cancer, and association with other cancers including ovarian, colon, prostate, pancreatic, endometrial, and male breast cancers and sarcomas [31-33].

A patient's chance of having a BRCA1 or BRCA2 germline mutation is highly dependent on the age and family history of breast and ovarian cancers [20,34-38]. BRCA1 mutations are observed in $6 \%$ to $16 \%$ of breast cancers diagnosed before the age of 36 years [34,36,38-40], while BRCA2 mutations account for a similar to the smaller or similar percentage in such young patients [40-42]. These genes may have greater contributions in early-onset breast cancer in defined populations with founder mutations. A multicenter study of 457 Ashkenazi-Jewish women with breast cancer reported that three founder mutations in $B R C A 1$ and BRCA2 were found in over $40 \%$ of breast cancers diagnosed before age 40 [38]. On the other hand, patients diagnosed at the age of 60 or older had mutation rates similar to that from population studies. A family history of ovarian or breast cancer, especially the number of first-degree relatives with breast cancer diagnosed before age 50, was an important predictor of BRCA1 and BRCA2 germline mutations in both affected and unaffected Ashkenazi-Jewish individuals [43-45].

In Asian patients, BRCA-associated breast cancers tend to develop at a younger age compared to sporadic breast cancers. It has been reported that in Korea, approximately $50 \%$ of breast cancer patients with BRCA1/2 mutations were younger than 40 years of age [25]. In a Chinese cohort, the mean age at breast cancer diagnosis in BRCA1/2 mutation carriers was 39-45 years [29,46,47], and $56.2 \%$ of BRCA1 mutation carriers and $33.3 \%$ of $B R C A 2$ mutation carriers were diagnosed with breast cancer before the age of 40 years compared with only $16.4 \%$ of noncarriers [47]. In a Japanese cohort, BRCA1/2 mutation carriers were significantly younger at the time of diagnosis compared with non-carriers [26]. A study from the Philippines reported that two-thirds of the Philippino breast cancer patients with BRCA1/2 mutations were under 45 years of age [ 48$]$.

Patients with BRCA1/2 mutations have higher incidences of contralateral and second ipsilateral primary breast cancers [18,49-52]. BRCA1/2 mutation carriers diagnosed with breast cancer have a long-term risk of developing a contralateral tumor as high as $60 \%$ to $70 \%[19,50,51]$. However, considering such clinical feature as an independent predictor of $B R C A 1 / 2$ germline mutation remains controversial $[35,41,53]$. BRCA1/2 mutations were found in 22.1\% (15/68) of bilateral breast cancer patients in Korea [25].

Most studies, including those in Asian patients, have reported that there is no significant difference in tumor size between 
BRCA1/2-associated and sporadic breast cancers [17,26,47,52,5458]. Nonetheless, a few studies have reported a larger tumor size at presentation in BRCA1/2-associated breast cancers [51,59,60], whereas others have reported the association of smaller tumor size and BRCA-associated tumors [29,61]. An earlier Chinese study reported that tumor size was significantly smaller in $B R C A$ carriers than in non-carriers [29]. However, in a recent large study on Chinese population, there was no difference in tumor size among BRCA1 carriers, BRCA2 carriers, and non-carriers [17].

Regarding lymph node status, several studies have shown that there was a tendency for $B R C A 1$ mutation carriers to have a higher percentage of lymph node-negative tumors compared with controls [35,49,51,55,61,62]. Earlier Chinese and Japanese cohort studies reported no differences in nodal status between BRCA1/2 mutation carriers and non-carriers [26,29,47]. However, a recent Chinese study reported a significantly higher rate of lymph node metastasis in BRCA2 mutation carriers compared with BRCA1 carriers and non-carriers [17].

The reported clinical outcomes of BRCA1/2 mutation carriers and non-carriers with breast cancer have been inconsistent. Some studies observed significantly worse survival in BRCA mutation carriers compared with sporadic breast cancer patients [63-68], whereas other studies have reported similar outcomes between BRCA mutation carriers and non-carriers $[60,69,70]$. Some earlier reports even suggested a superior outcome in hereditary breast cancer [71,72]. A large population-based study reported that 10-year survival rates were similar between $B R C A$ mutation carriers and non-carriers [73]. Bordeleau et al. [74] also reported that prognosis of BRCA1/2-associated and sporadic breast cancers appeared to be similar based on their review of the literature. However, a meta-analysis assessing the effect of BRCA1/2 mutations on survival by Lee et al. [75] concluded that BRCA1, but not BRCA2, mutation decreases short-term and long-term overall survivals and short-term progression-free survival. The majority of these results were from Western studies, and there have been few reports comparing the clinical outcomes of BRCA mutation carriers and non-carriers in Asian patients. In a Chinese cohort, BRCA1/2 mutation was not associated with breast cancer-specific survival, and BRCA1 mutation was not proven as an independent prognostic factor [76]. Another large Chinese cohort study reported no difference in disease-free survival among BRCA1 carriers, BRCA2 carriers, and non-carriers [17]. General opinion seems to be that BRCA1/2 mutation carriers and non-carriers have a similar prognosis.

It remains inconclusive whether $B R C A$ mutation carriers are more likely to develop local recurrence than non-carriers. Some studies have reported similar rates of local recurrence between BRCA mutation carriers and non-carriers $[54,64,77,78]$ while others have observed more frequent ipsilateral breast cancer recurrence among BRCA mutation carriers $[29,66,79,80]$.

\section{PATHOLOGICAL CHARACTERISTICS OF BRCA-ASSOCIATED BREAST CANCER}

\section{Histological features}

The most common histological subtype in hereditary breast cancers is invasive ductal carcinoma-not otherwise specified, and this type of breast cancer seems to be more frequent in BRCA1/2 mutation carriers than in non-carriers [78]. However, BRCA1associated breast cancers have consistently been shown to have a higher frequency of medullary and atypical medullary carcinomas than BRCA2-associated and sporadic breast cancers. In a report by the Breast Cancer Linkage Consortium (BCLC), which is the most extensive series on the histological features of $B R C A$ associated breast cancer, BRCA1 mutation carriers were found to have a higher incidence of medullary or atypical medullary carcinomas (13\%) than BRCA2 carriers (3\%) and non-carriers (2\%) [81]. In a report by Eisinger et al. [82], 19\% of BRCA1associated cases were typical medullary type. Invasive lobular carcinoma seems to be more frequent in BRCA2-associated breast cancers [78]. Although the BCLC did not report a higher frequency of lobular cancers in BRCA2-associated breast cancers [81], Armes et al. [56] found that pleomorphic lobular carcinomas and extensive intraductal carcinomas were more frequent in BRCA2 mutation carriers. Marcus et al. [49] reported a higher incidence of the 'tubular lobular group' in BRCA2-associated tumors, which includes invasive lobular, tubular, and cribriform carcinomas. A lobular phenotype is rarely found in BRCA1-associated breast cancers.

A more detailed examination of the cytological and architectural features of $B R C A$-associated tumors has been reported in a complementary collaborative study by the BCLC [83]. BRCA1associated breast cancers were associated with pushing margins, marked nuclear atypia, high mitotic frequency, necrotic foci, and prominent lymphocytic infiltration, some of which features define medullary carcinoma (Fig. 1). On the contrary, BRCA2-associated cancers had less tubular differentiation, some tendency for pushing margins, and less mitotic activity compared with sporadic breast cancers. A multivariate analysis comparing BRCA1and BRCA2-associated breast cancers revealed that higher mitotic count $(\mathrm{p}<.001)$ and lymphocytic infiltration $(\mathrm{p}=.001)$ in BRCA1-associated cancers and defective tubule formation 

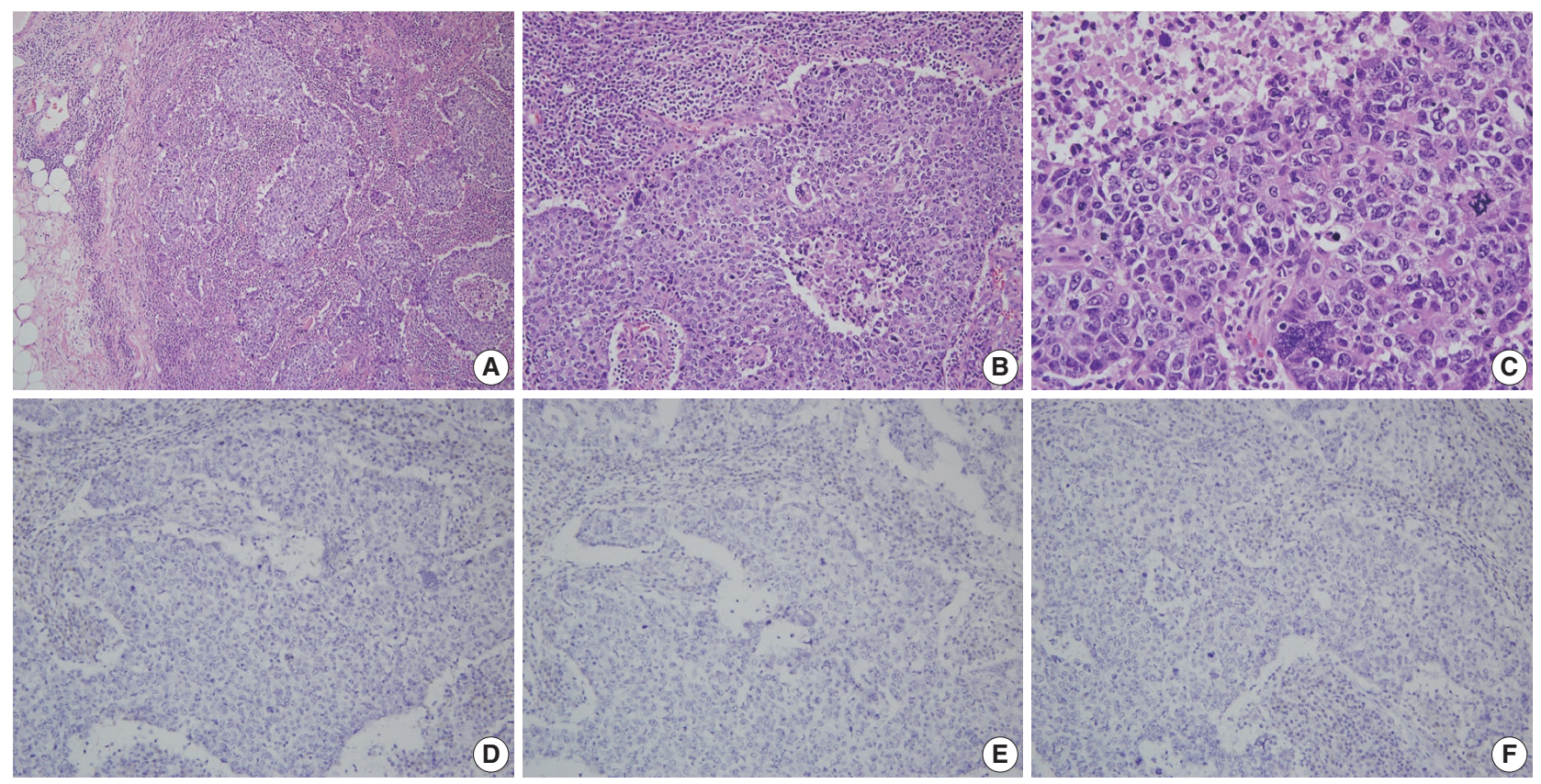

Fig. 1. A representative example of BRCA1-associated breast cancer diagnosed with invasive carcinoma with medullary features. (A) Low power view reveals a well-circumscribed tumor with a pushing margin and heavy lymphocytic infiltration. There are no desmoplastic stroma and no carcinoma in situ component. (B) The tumor shows a syncytial growth pattern with central necrosis. (C) Tumor cells show marked nuclear pleomorphism and frequent mitoses. Estrogen receptor (D), progesterone receptor (E), and human epidermal growth factor receptor-2 (F) are all negative on immunohistochemistry.

$(\mathrm{p}<.001)$ in BRCA2-associated cancers were the only statistically significant features.

A consistent feature of BRCA1-associated tumors is high histologic grade. The incidence of grade III tumors has been reported to range from $66 \%$ to $84 \%$ in BRCA1 mutation carriers and $30 \%$ to $40 \%$ in sporadic controls $[81,84-86]$. A detailed analysis of the BCLC report showed tumor specimens from $B R$ CA1-associated breast cancer patients had less tubule formation, higher nuclear pleomorphism and higher mitotic activity compared with tumor specimens from age-matched sporadic controls [81]. BRCA2-associated tumors also tend to be of higher grade compared with sporadic tumors; however, this association is weaker than that for BRCA1-associated tumors. In the BCLC report, $66 \%$ of $B R C A 1$ tumors, $41 \%$ of $B R C A 2$ tumors, and $36 \%$ of sporadic tumors were grade III [81]. Most BRCA2 tumors are grade II or III, and in comparison with sporadic tumors, show less tubule formation but similar cellular pleomorphism and mitotic counts (Fig. 2) [81]. However, in some series, nuclear pleomorphism and mitotic rates have been reported to be higher in BRCA2 tumors than in sporadic tumors [87].

\section{Hormonal receptors and human epidermal growth factor receptor-2 status}

Expression status of estrogen receptor (ER), progesterone re- ceptor (PR), and human epidermal growth factor receptor-2 (HER2) have critical clinical implications for breast cancer treatment and prognosis. BRCA1-associated breast cancers have strong associations with ER and PR expression [17,56,64,85,86,88-91]. The ER status has been reported to be negative in $71 \%$ to $90 \%$ of BRCA1-associated breast cancers in different series [17,56, $85,88,89$ ]. Lakhani et al. [88] reported that $90 \%$ of BRCA1-associated breast cancers showed negative ER expression compared with $35 \%$ of controls. Lang et al. [17] reported that the rate of ER negativity in tumors of BRCA1 carriers, BRCA2 carriers, and non-carriers among Chinese patients was $71.2 \%$, $27.1 \%$, and $42.8 \%$, respectively. Younger age and higher tumor grade have been suggested to contribute to the lower rate of ER expression in BRCA1-associated breast cancers. However, even taking into account the earlier age of onset of BRCA1-associated breast cancers, ER-positive breast cancers are clearly underrepresented in this group. The likelihood of ER negativity was reported to be 4.8 times higher in high-grade BRCA1-associated tumors than in high-grade sporadic tumors [90]. PR expression has also been reported to be lower in BRCA1-associated tumors than sporadic tumors $[17,56,85,88,89]$. Lang et al. [17] reported the rate of $\mathrm{PR}$ negativity in tumors of $B R C A 1$ carriers, BRCA2 carriers, and non-carriers as $71.2 \%, 31.8 \%$, and $47.7 \%$, respectively. In contrast to $B R C A 1$-associated tumors, ER and 

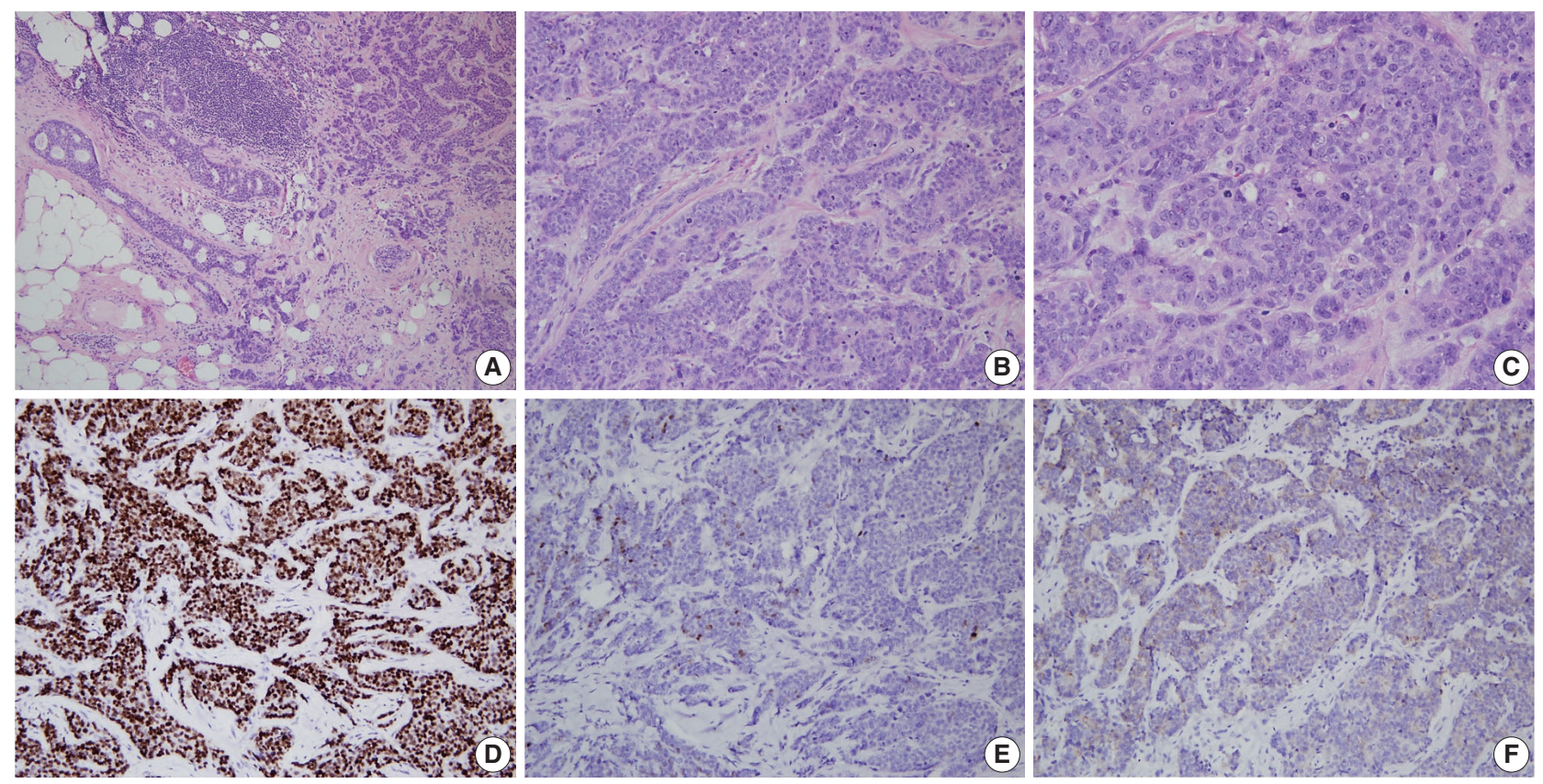

Fig. 2. A representative example of BRCA2-associated breast cancer diagnosed as high grade invasive ductal carcinoma (invasive carcinoma of no special type). (A) Low power view reveals an ill-defined tumor with an infiltrative margin. The tumor reveals desmoplastic stroma and ductal carcinoma in situ component on the left. $(B, C)$ The tumor shows less tubule formation, moderate nuclear pleomorphism, and frequent mitoses. Estrogen receptor $(\mathrm{D})$ is diffuse positive, progesterone receptor $(\mathrm{E})$ is focal positive, and human epidermal growth factor receptor-2 (F) is 1+/3 on immunohistochemistry.

PR expression is similar between BRCA2-associated and sporadic breast cancers; the reported ER and PR expression levels in BRCA2-associated breast cancers are approximately 65\%$72 \%$ and 40\%-68\%, respectively (Fig. 2) [17,56,64,88].

Data on HER2 expression in BRCA-associated tumors vary among series and is probably due to technical differences. However, most studies have reported that the frequency of HER2 overexpression in both BRCA1- and BRCA2-associated tumors ranges from $0 \%$ to $8 \%[17,55,88,89]$. HER2 overexpression is classically associated with aneuploidy and high grade, which are two features encountered more frequently in BRCA1-associated tumors. Despite this association, a significantly lower incidence of HER2 overexpression has been observed among BRCA1-associated breast cancers $[17,55,85,88,89,92-94]$. The low incidence of HER2/neu amplification in BRCA1-associated carcinomas may be due to physical codeletion of one HER2/neu allele and nearby sequences during the loss of heterozygosity at the BRCA1 locus as suggested in one study [94]. The reason behind the low incidence of HER2/neu amplification in BRCA2-associated tumors remains yet to be elucidated.

Triple-negative breast cancers (TNBCs), which lack expression of ER, PR, and HER2, comprise $15 \%$ to $20 \%$ of all sporadic breast cancers $[9,95]$. Most studies have shown a significantly higher frequency (57\% to $75 \%$ ) of the triple-negative phenotype among BRCA1 mutation carriers (Fig. 1) [9,95-97]. The incidence of BRCA1 mutations in TNBC patients has been reported to be $7.5 \%$ to $15.6 \%[9,97,98]$. Sharma et al. [98] evaluated the prevalence of $B R C A 1 / 2$ mutations in 207 TNBC patients and reported that deleterious $B R C A 1 / 2$ mutations were present in $15.4 \%$ of patients with BRCA1 in $11.1 \%$ and BRCA2 in $4.3 \%$ of patients. However, the mutation prevalence differed according to patient age: it was $27.6 \%, 11.4 \%$, and $4.9 \%$ in patients aged $\leq 50$ years, $51-60$ years, and $\geq 61$ years, respectively [98]. A higher incidence of the triple-negative phenotype (50\% to 100\%) among Asian patients with BRCA1 mutations has also been reported [17,29,30,46,47,58,76,99]. The reported incidence of BRCA1 mutation among Asian patients with TNBC is $9.4 \%$ to $36.8 \%$ [29,47,76,99]. A recent Chinese cohort study reported the rate of triple-negative phenotype in BRCA1 carriers, BRCA2 carriers, and non-carriers was $61.6 \%, 23.9 \%$, and $33.1 \%$, respectively [17]. The rate of BRCA1 mutation among patients with TNBC was $11.1 \%$ [17].

Key pathological characteristics of BRCA1- and BRCA2-associated breast cancers are summarized in Table 1.

\section{Carcinoma in situ}

The natural history of hereditary breast cancers from morphologically normal epithelium to invasive cancer is not well known. 
Table 1. Key pathological characteristics of BRCA1- and BRCA2-associated breast cancers $[9,55,63,80,82,84,87,88,94-96,103]$

\begin{tabular}{|c|c|c|}
\hline & BRCA1 & BRCA2 \\
\hline Histology & $\begin{array}{l}\text { Ductal, no special type (75\%); medullary or atypical } \\
\text { medullary (10\%-20\%); rare lobular }\end{array}$ & $\begin{array}{l}\text { Ductal, no special type (75\%); medullary or atypical } \\
\text { medullary (<5\%); lobular or ductal with lobular features } \\
\text { more common than in BRCA1 ( 10\%) }\end{array}$ \\
\hline Mitosis & High & Low \\
\hline Prominent lymphocytic infiltration & Often & Rare \\
\hline Histologic grade & High (grade III, 71\%-75\%) & $\begin{array}{l}\text { Intermediate to high (grade II, } 43 \%-45 \% \text {; grade III, } \\
45 \%-50 \% \text { ) }\end{array}$ \\
\hline ER & Negative (73\%-90\%) & Positive (65\%-77\%) \\
\hline PR & Negative (79\%-81\%) & Positive (40\%-64\%) \\
\hline HER2 & Negative (86\%-95\%) & Negative (72\%-95\%) \\
\hline Triple-negative phenotype & Common (57\%-75\%) & Rare \\
\hline Associated in situ carcinoma & Rare & Common \\
\hline Others & $\begin{array}{l}\text { p53 positive (50\%-53\%); CK5 positive (50\%); bcl-2, low; } \\
\text { CDKN2A, low; cyclin D1 negative (90\%) }\end{array}$ & $\begin{array}{l}\text { p53 positive (40\%-52\%); CK5 negative (90\%); bcl-2, high; } \\
\text { CDKN2A, high; cyclin D1 positive (60\%) }\end{array}$ \\
\hline
\end{tabular}

ER, estrogen receptor; PR, progesterone receptor; HER2, human epidermal growth factor receptor-2; CK, cytokeratin; bcl-2, B-cell leukemia/lymphoma-2; CDKN2A, Cyclin dependent kinase inhibitor 2A.

It is difficult to assess and compare the incidence of in situ carcinoma between studies, and the incidence of in situ lesions in the absence of a concomitant invasive component has not been established in familial breast cancers.

Ductal carcinoma in situ (DCIS) around the invasive lesion is reported to be less common in BRCA1 mutation carriers than in controls $[78,81,84]$. However, the results for lobular carcinoma in situ (LCIS) are uncertain [78]. In the BCLC study, BRCA1 mutation carriers showed less DCIS around the invasive cancer compared to controls ( $41 \%$ vs. $56 \%, \mathrm{p}=.001$ ) [81]. LCIS was less common in familial cancers $(\mathrm{p}=.013)$ with no significant difference between $B R C A 1$ and $B R C A 2$ mutation carriers [81]. BRCA1 and BRCA2 mutations were found in three $(0.8 \%)$ and nine (2.4\%) of 369 DCIS cases, respectively [100].

Prophylactic mastectomy specimens have been used to investigate the different stages of breast cancer development in BRCA1/2 mutation carriers [84]. Hoogerbrugge et al. [101] assessed prophylactic mastectomy specimens of 67 women who had an extremely high genetic risk of breast cancer (66\% of patients were $B R C A 1$ or BRCA2 mutation carriers) and reported that one or more types of high-risk histopathological lesions, such as DCIS, LCIS, atypical ductal hyperplasia (ADH), and atypical lobular hyperplasia (ALH), were present in 57\% of the women [101]. Kauff et al. [102] also reported that lesions with risks of developing subsequent malignancy (DCIS, LCIS, ADH, and ALH) are more common in prophylactic mastectomy specimens from women with BRCA mutations than in autopsy specimens from unaffected women of unknown genetic predisposition.

Adem et al. [103] evaluated therapeutic mastectomy and prophylactic mastectomy specimens from high-risk women with or without BRCA1/2 mutations. They observed that prolifera- tive fibrocystic changes were less prevalent in BRCA1/2 mutation carriers (7\%) than controls (25\%) and non-carriers with a family history of breast cancer (22\%-33\%). However, the prevalence of DCIS was not different among the groups (50\%-60\%), and invasive carcinomas were of higher grade in the BRCA1/2 mutation carriers compared with controls and non-carriers. Based on these findings, they suggested that breast cancer progression is accelerated in BRCA1/2-mutation carriers.

\section{Pathologic data from the Consortium of Investigators of Modifiers of $B R C A 1 / 2$}

The comprehensive pathology data of 4,325 BRCA1 and 2,568 BRCA2 mutation carriers were reported in 2012 from the Consortium of Investigators of Modifiers of BRCA1/2 (CIM$\mathrm{BA})$, the most extensive collaborative study of $B R C A 1$ and BRCA2 mutation carriers [96]. In both BRCA1 and BRCA2 carriers diagnosed with breast cancer, invasive ductal carcinoma of no special type was the predominant histologic subtype. Medullary and atypical medullary carcinomas were more likely to be BRCA1-related $\left(\mathrm{p}=2.3 \times 10^{-15}\right)$, while lobular carcinomas were $B R C A 2$-related $\left(\mathrm{p}=4.4 \times 10^{-14}\right)$. As for receptor status, $78 \%, 79 \%, 90 \%$, and $69 \%$ of tumors diagnosed in BRCA1 carriers were ER-negative, PR-negative, HER2-negative, and triple-negative, respectively, whereas $23 \%, 36 \%, 87 \%$, and $16 \%$ of tumors from $B R C A 2$ carriers were ER-negative, PR-negative, HER2-negative, and triple-negative. The proportion of ER-negative breast cancers decreased with age among $B R C A 1$ carriers $\left(\mathrm{p}=1.2 \times 10^{-5}\right)$ but increased with age among BRCA2 carriers $\left(\mathrm{p}=6.8 \times 10^{-6}\right)$. As for the proportion of TNBCs, it decreased with age in BRCA1 carriers but increased with age in BRCA2 carriers. In BRCA1 and BRCA2 carriers alike, ER-negative tu- 
mors had higher histologic grade than ER-positive tumors.

\section{REPORTS ASSESSING THE CHARACTERISTICS OF BRCA-ASSOCIATED BREAST CANCER IN ASIAN PATIENTS}

To date, few studies have assessed characteristics of BRCA1/2associated breast cancer in Asian patients. In 2009, Kwong et al. [29] reported the clinicopathological characteristics of Chinese patients with BRCA-associated breast cancer. Among 226 high-risk Hong Kong Chinese women, 28 women (12.4\%) carried BRCA mutations (BRCA1 mutation, 11 patients; BRCA2 mutations, 17 patients), and $55.6 \%$ of these carriers were diagnosed with breast cancer before age 40 compared with 36.0\% of non-carriers $(\mathrm{p}=.05)$. BRCA mutation carriers were more likely to have a family history of breast and ovarian cancers, highgrade cancers, and TNBCs. The prevalence of TNBC was significantly higher in BRCA1 carriers (67.7\%) than in BRCA2 carriers (35.3\%) and non-carriers (25.6\%). ER-negative cancer was significantly associated with $B R C A 1$ mutations, especially in patients under 40 years of age.

In 2014, Yu et al. [58] compared the characteristics of breast cancers from 181 BRCA1/2 mutation carriers cases (80 patients with BRCA1 mutation and 101 patients with BRCA2 mutation) and 55,387 sporadic breast cancers from the Korean Breast Cancer Registry. In this report, median patient age was significantly lower in the BRCA1 and BRCA2 mutation groups than in the registry group (37 years and 41 years vs. 48 years; $\mathrm{p}<$ .001 for both). Tumor size was not different between the BRCA1 and $B R C A 2$ groups and the registry group. The proportion of patients with axillary node metastasis was not significantly different between the BRCA1 and registry groups; however, axillary nodal involvement was present more often in the BRCA2 group than in the registry group ( $45.5 \%$ vs. $33.5 \%, \mathrm{p}=.002)$. Tumor size and axillary nodal involvement did not have significant correlations in the BRCA1 and BRCA2 groups. Tumors of the $B R C A 1$ group were of higher grade compared with those of the registry group $(64.3 \%$ vs. $27.5 \%, \mathrm{p}<.001)$. The BRCA1 group had a higher proportion of hormone receptor-negative tumors and lower proportion of HER2-overexpressing tumors compared to the registry group. TNBCs were more prevalent in the BRCA1 group than in the registry group (61.3\% vs. $12.4 \%$, $\mathrm{p}<.001)$. In contrast, hormone receptor expression was not significantly different between the BRCA2 group and registry group. The frequency of DCIS was lower in the BRCA1 (3.7\%) and BRCA2 (5\%) groups than in the registry group (10.3\%).
Recently, Lang et al. [17] reported the prevalence of $B R C A$ mutation and features of $B R C A$-associated breast cancer in Chinese patients by using next-generation sequencing on 2,991 breast cancer patients and 1,043 healthy individuals as controls. BRCA mutations were present in $9.1 \%(232 / 2,560)$ of patients with at least one risk factor for hereditary breast cancer compared to $3.5 \%(15 / 431)$ in sporadic patients and $0.38 \%(4 / 1,043)$ in healthy controls. Family history of breast/ovarian cancer, young age, negative HER2, high Ki-67 index, and high tumor grade were associated with $B R C A$ mutations. BRCA1 carriers were more likely to be ER- or PR-negative than BRCA1 non-carriers, whereas BRCA2-mutated breast cancers were more likely to be ER- or PR-positive. BRCA1-mutated patients also presented a higher stage at the time of diagnosis, and BRCA2 mutation carriers showed more positive lymph nodes. There were no differences in disease-free survival among $B R C A 1$ carriers, $B R C A 2$ carriers, and non-carriers. However, among the non-TNBC patients, BRCA2 mutation carriers showed decreased disease-free survival compared to BRCA2 mutation non-carriers (hazard ratio, 1.892; 95\% confidence interval, 1.132 to 3.161; $\mathrm{p}=.013$ ).

In 2011, the Asian BRCA (ABRCA) Consortium was established to share knowledge and conduct collaborative researches on hereditary breast and ovarian cancer (HBOC) in Asia. To date, the ABRCA Consortium has members from 14 Asian countries (Korea, Japan, Malaysia, Singapore, Hong Kong, China, Indonesia, Thailand, the Philippines, India, Bangladesh, Pakistan, Taiwan, and Vietnam). The ABRCA Consortium has held regular meetings annually since 2011 and is open to new members who wish to participate in collaborative researches in Asia. The ABRCA working groups are conducting studies to assess the $B R C A$ mutation spectrum and founder mutations in Asia as well as the status of genetic counseling and genetic testing for HBOC in Asian countries. Lifestyle modifiers of breast cancer and estimated penetrance of $B R C A$ mutations in Asians may become clearer with the groups' efforts. A more comprehensive understanding of the clinicopathological characteristics of BRCA1/2associated breast cancer in Asian populations is expected through this international collaboration.

\section{CONCLUSION}

BRCA1/2 germline mutations account for the majority of HBOCs. Ever since the BRCA genes were recognized, many have attempted to define the clinicopathological characteristics of $B R C A$-associated breast cancer in relation to sporadic breast cancer. BRCA1/2-associated breast cancers have certain distinc- 
tive clinical features such as younger age at onset, higher prevalence of bilateral breast cancer, male family members with breast cancer, and association with other cancers in the ovary, colon, prostate, pancreas, and endometrium. BRCA1/2-associated breast cancers seem to have a similar prognosis as sporadic breast cancers. BRCA1-associated cancers have characteristic histopathologic features compared with sporadic cases: they are usually high grade, poorly differentiated, and infiltrating ductal carcinomas with a triple-negative phenotype. Medullary carcinomas are also more frequent in BRCA1 mutation carriers. BRCA2associated breast cancers seem to share similar pathologic characteristics with non-carriers with the exception of an increased frequency of high-grade tumors. Evidence to date suggests that the clinicopathological characteristics of BRCA-associated breast cancer are not different between Asian and Caucasian patients.

\section{Ethics Statement}

Not applicable.

\section{ORCID}

Eun-Kyu Kim https://orcid.org/0000-0003-1318-0939

So Yeon Park https://orcid.org/0000-0002-0299-7268

Sung-Won Kim https://orcid.org/0000-0001-5687-1380

\section{Author Contributions}

Project administration: SWK. Supervision: SWK. Writing—original draft: EKK. Writing—review \& editing: SWK, SYP.

\section{Conflicts of Interest}

S.Y.P. is the Editor-in-Chief of the Journal of Pathology and Translational Medicine and was not involved in the editorial evaluation or decision to publish this article. All remaining authors declare that they have no potential conflicts of interest.

\section{Funding Statement}

The present research has been supported by Korea Breast Cancer Foundation (KBCF-2017R008).

\section{References}

1. Torre LA, Bray F, Siegel RL, Ferlay J, Lortet-Tieulent J, Jemal A. Global cancer statistics, 2012. CA Cancer J Clin 2015; 65: 87-108.

2. Ripperger T, Gadzicki D, Meindl A, Schlegelberger B. Breast cancer susceptibility: current knowledge and implications for genetic counselling. Eur J Hum Genet 2009; 17: 722-31.

3. Fackenthal JD, Olopade OI. Breast cancer risk associated with $B R C A 1$ and BRCA2 in diverse populations. Nat Rev Cancer 2007; 7: $937-48$

4. Ford D, Easton DF, Stratton M, et al. Genetic heterogeneity and penetrance analysis of the BRCA1 and BRCA2 genes in breast cancer families. The Breast Cancer Linkage Consortium. Am J Hum Genet 1998; 62: 676-89.

5. Antoniou A, Pharoah PD, Narod S, et al. Average risks of breast and ovarian cancer associated with BRCA1 or BRCA2 mutations detected in case Series unselected for family history: a combined analysis of 22 studies. Am J Hum Genet 2003; 72: 1117-30.

6. Chen S, Parmigiani G. Meta-analysis of BRCA1 and BRCA2 penetrance. J Clin Oncol 2007; 25: 1329-33.

7. Ferla R, Calo V, Cascio S, et al. Founder mutations in BRCA1 and BRCA2 genes. Ann Oncol 2007; 18 Suppl 6: vi93-8.

8. Daly MB, Axilbund JE, Buys S, et al. Genetic/familial high-risk assessment: breast and ovarian. J Natl Compr Canc Netw 2010; 8: 562-94.

9. Gonzalez-Angulo AM, Timms KM, Liu S, et al. Incidence and outcome of BRCA mutations in unselected patients with triple receptor-negative breast cancer. Clin Cancer Res 2011; 17: 1082-9.

10. Jemal A, Bray F, Center MM, Ferlay J, Ward E, Forman D. Global cancer statistics. CA Cancer J Clin 2011; 61: 69-90.

11. Shin HR, Carlos MC, Varghese C. Cancer control in the Asia Pacific region: current status and concerns. Jpn J Clin Oncol 2012; 42: 867-81.

12. Ko BS, Noh WC, Kang SS, et al. Changing patterns in the clinical characteristics of Korean breast cancer from 1996-2010 using an online nationwide breast cancer database. J Breast Cancer 2012; 15: 393-400.

13. Kim H, Choi DH. Distribution of BRCA1 and BRCA2 mutations in Asian patients with breast cancer. J Breast Cancer 2013; 16: 35765.

14. Yang L, Parkin DM, Ferlay J, Li L, Chen Y. Estimates of cancer incidence in China for 2000 and projections for 2005. Cancer Epidemiol Biomarkers Prev 2005; 14: 243-50.

15. Kurian AW, Fish K, Shema SJ, Clarke CA. Lifetime risks of specific breast cancer subtypes among women in four racial/ethnic groups. Breast Cancer Res 2010; 12: R99.

16. Anglian Breast Cancer Study Group. Prevalence and penetrance of BRCA1 and BRCA2 mutations in a population-based series of breast cancer cases. Anglian Breast Cancer Study Group. Br J Cancer 2000; 83: 1301-8.

17. Lang GT, Shi JX, Hu X, et al. The spectrum of BRCA mutations and characteristics of $B R C A$-associated breast cancers in China: screening of 2,991 patients and 1,043 controls by next-generation sequencing. Int J Cancer 2017; 141: 129-42.

18. Ford D, Easton DF, Bishop DT, Narod SA, Goldgar DE. Risks of cancer in BRCA1-mutation carriers. Breast Cancer Linkage Consortium. Lancet 1994; 343: 692-5.

19. Easton DF, Ford D, Bishop DT. Breast and ovarian cancer incidence in BRCA1-mutation carriers. Breast Cancer Linkage Consortium. Am J Hum Genet 1995; 56: 265-71.

20. Struewing JP, Hartge P, Wacholder S, et al. The risk of cancer associated with specific mutations of BRCA1 and BRCA2 among Ashkenazi Jews. N Engl J Med 1997; 336: 1401-8.

21. Han SA, Park SK, Ahn SH, et al. The breast and ovarian cancer risks in Korea due to inherited mutations in BRCA1 and BRCA2: a preliminary report. J Breast Cancer 2009; 12: 92-9.

22. Ikeda N, Miyoshi Y, Ikeda N, Yoneda K, Kinoshita M, Noguchi S. Frequency of $B R C A 1$ and $B R C A 2$ germline mutations detected by protein truncation test and cumulative risks of breast and ovarian cancer among mutation carriers in Japanese breast cancer families. J Korean Breast Cancer Soc 2002; 5: 194-201.

23. Robson M, Im SA, Senkus E, et al. Olaparib for metastatic breast cancer in patients with a germline BRCA mutation. $\mathrm{N}$ Engl J Med 2017; 377: 523-33. 
24. Litton JK, Rugo HS, Ettl J, et al. Talazoparib in patients with advanced breast cancer and a germline BRCA mutation. $\mathrm{N}$ Engl J Med 2018; 379: 753-63.

25. Han SA, Kim SW, Kang E, et al. The prevalence of BRCA mutations among familial breast cancer patients in Korea: results of the Korean Hereditary Breast Cancer study. Fam Cancer 2013; 12: 7581.

26. Sugano K, Nakamura S, Ando J, et al. Cross-sectional analysis of germline $B R C A 1$ and $B R C A 2$ mutations in Japanese patients suspected to have hereditary breast/ovarian cancer. Cancer Sci 2008; 99: 1967-76.

27. Kwong A, Ng EK, Wong CL, et al. Identification of BRCA1/2 founder mutations in Southern Chinese breast cancer patients using gene sequencing and high resolution DNA melting analysis. PLoS One 2012; 7: e43994.

28. Valarmathi MT, Sawhney M, Deo SS, Shukla NK, Das SN. Novel germline mutations in the BRCA1 and BRCA2 genes in Indian breast and breast-ovarian cancer families. Hum Mutat 2004; 23: 205.

29. Kwong A, Wong LP, Wong HN, et al. Clinical and pathological characteristics of Chinese patients with BRCA related breast cancer. Hugo J 2009; 3: 63-76.

30. Yip CH, Taib NA, Choo WY, Rampal S, Thong MK, Teo SH. Clinical and pathologic differences between BRCA1-, BRCA2-, and non- $B R C A$-associated breast cancers in a multiracial developing country. World J Surg 2009; 33: 2077-81.

31. Wooster R, Neuhausen SL, Mangion J, et al. Localization of a breast cancer susceptibility gene, BRCA2, to chromosome 13q1213. Science 1994; 265: 2088-90.

32. Breast Cancer Linkage Consortium. Cancer risks in BRCA2 mutation carriers. J Natl Cancer Inst 1999; 91: 1310-6.

33. Thompson D, Easton DF; Breast Cancer Linkage Consortium. Cancer incidence in BRCA1 mutation carriers. J Natl Cancer Inst 2002; 94: 1358-65.

34. FitzGerald MG, MacDonald DJ, Krainer M, et al. Germ-line BRCA1 mutations in Jewish and non-Jewish women with earlyonset breast cancer. N Engl J Med 1996; 334: 143-9.

35. Shattuck-Eidens D, Oliphant A, McClure M, et al. BRCA1 sequence analysis in women at high risk for susceptibility mutations: risk factor analysis and implications for genetic testing. JAMA 1997; 278: 1242-50.

36. Malone KE, Daling JR, Thompson JD, O’Brien CA, Francisco LV, Ostrander EA. BRCA1 mutations and breast cancer in the general population: analyses in women before age 35 years and in women before age 45 years with first-degree family history. JAMA 1998; 279: 922-9.

37. Hodgson SV, Heap E, Cameron J, et al. Risk factors for detecting germline BRCA1 and BRCA2 founder mutations in Ashkenazi Jewish women with breast or ovarian cancer. J Med Genet 1999; 36: 369-73.

38. Warner E, Foulkes W, Goodwin P, et al. Prevalence and penetrance of BRCA1 and BRCA2 gene mutations in unselected Ashkenazi Jewish women with breast cancer. J Natl Cancer Inst 1999; 91: 12417.

39. Langston AA, Malone KE, Thompson JD, Daling JR, Ostrander EA. BRCA1 mutations in a population-based sample of young women with breast cancer. N Engl J Med 1996; 334: 137-42.

40. Peto J, Collins N, Barfoot R, et al. Prevalence of BRCA1 and
BRCA2 gene mutations in patients with early-onset breast cancer. J Natl Cancer Inst 1999; 91: 943-9.

41. Ligtenberg MJ, Hogervorst FB, Willems HW, et al. Characteristics of small breast and/or ovarian cancer families with germline mutations in BRCA1 and BRCA2. Br J Cancer 1999; 79: 1475-8.

42. Krainer M, Silva-Arrieta S, FitzGerald MG, et al. Differential contributions of BRCA1 and BRCA2 to early-onset breast cancer. $\mathrm{N}$ Engl J Med 1997; 336: 1416-21.

43. Hartge P, Struewing JP, Wacholder S, Brody LC, Tucker MA. The prevalence of common BRCA1 and BRCA2 mutations among Ashkenazi Jews. Am J Hum Genet 1999; 64: 963-70.

44. Hopper JL, Jenkins MA. Modeling the probability that Ashkenazi Jewish women carry a founder mutation in BRCA1 or BRCA2. Am J Hum Genet 1999; 65: 1771-6.

45. Foulkes WD, Brunet JS, Warner E, et al. The importance of a family history of breast cancer in predicting the presence of a $B R C A$ mutation. Am J Hum Genet 1999; 65: 1776-9.

46. Li WF, Hu Z, Rao NY, et al. The prevalence of BRCA1 and BRCA2 germline mutations in high-risk breast cancer patients of Chinese Han nationality: two recurrent mutations were identified. Breast Cancer Res Treat 2008; 110: 99-109.

47. Zhang J, Pei R, Pang Z, et al. Prevalence and characterization of $B R C A 1$ and BRCA2 germline mutations in Chinese women with familial breast cancer. Breast Cancer Res Treat 2012; 132: 421-8.

48. De Leon Matsuda ML, Liede A, Kwan E, et al. BRCA1 and BRCA2 mutations among breast cancer patients from the Philippines. Int $J$ Cancer 2002; 98: 596-603.

49. Marcus JN, Watson P, Page DL, et al. Hereditary breast cancer: pathobiology, prognosis, and $B R C A 1$ and $B R C A 2$ gene linkage. Cancer 1996; 77: 697-709.

50. Johannsson OT, Ranstam J, Borg A, Olsson H. Survival of BRCA1 breast and ovarian cancer patients: a population-based study from southern Sweden. J Clin Oncol 1998; 16: 397-404.

51. Robson M, Gilewski T, Haas B, et al. BRCA-associated breast cancer in young women. J Clin Oncol 1998; 16: 1642-9.

52. Noguchi S, Kasugai T, Miki Y, Fukutomi T, Emi M, Nomizu T. Clinicopathologic analysis of BRCA1- or BRCA2-associated hereditary breast carcinoma in Japanese women. Cancer 1999; 85: 2200-5.

53. Couch FJ, DeShano ML, Blackwood MA, et al. BRCA1 mutations in women attending clinics that evaluate the risk of breast cancer. N Engl J Med 1997; 336: 1409-15.

54. Verhoog LC, Brekelmans CT, Seynaeve C, et al. Survival and tumour characteristics of breast-cancer patients with germline mutations of BRCA1. Lancet 1998; 351: 316-21.

55. Johannsson OT, Idvall I, Anderson C, et al. Tumour biological features of BRCA1-induced breast and ovarian cancer. Eur J Cancer 1997; 33: 362-71.

56. Armes JE, Egan AJ, Southey MC, et al. The histologic phenotypes of breast carcinoma occurring before age 40 years in women with and without $B R C A 1$ or $B R C A 2$ germline mutations: a populationbased study. Cancer 1998; 83: 2335-45.

57. Garcia-Patiño E, Gomendio B, Provencio M, et al. Germ-line BRCA1 mutations in women with sporadic breast cancer: clinical correlations. J Clin Oncol 1998; 16: 115-20.

58. Yu JH, Lee JW, Son BH, et al. Characteristics of BRCA1/2 mutation-positive breast cancers in Korea: a comparison study based on multicenter data and the Korean Breast Cancer Registry. J Breast 
Cancer 2014; 17: 129-35.

59. Foulkes WD, Wong N, Brunet JS, et al. Germ-line BRCA1 mutation is an adverse prognostic factor in Ashkenazi Jewish women with breast cancer. Clin Cancer Res 1997; 3(12 Pt 1): 2465-9.

60. Verhoog LC, Brekelmans CT, Seynaeve C, et al. Survival in hereditary breast cancer associated with germline mutations of BRCA2. J Clin Oncol 1999; 17: 3396-402.

61. Wagner TM, Moslinger RA, Muhr D, et al. BRCA1-related breast cancer in Austrian breast and ovarian cancer families: specific BRCA1 mutations and pathological characteristics. Int J Cancer 1998; 77: 354-60.

62. Eisinger F, Noguès C, Birnbaum D, Jacquemier J, Sobol H. Low frequency of lymph-node metastasis in BRCA1-associated breast cancer. Lancet 1998; 351: 1633-4.

63. Stoppa-Lyonnet D, Ansquer Y, Dreyfus H, et al. Familial invasive breast cancers: worse outcome related to BRCA1 mutations. J Clin Oncol 2000; 18: 4053-9.

64. Robson ME, Chappuis PO, Satagopan J, et al. A combined analysis of outcome following breast cancer: differences in survival based on BRCA1/BRCA2 mutation status and administration of adjuvant treatment. Breast Cancer Res 2004; 6: R8-17.

65. Ansquer Y, Gautier C, Fourquet A, Asselain B, Stoppa-Lyonnet D. Survival in early-onset $B R C A 1$ breast-cancer patients. Institut $\mathrm{Cu}$ rie Breast Cancer Group. Lancet 1998; 352: 541.

66. Moran MS, Yang Q, Harris LN, Jones B, Tuck DP, Haffty BG. Long-term outcomes and clinicopathologic differences of AfricanAmerican versus white patients treated with breast conservation therapy for early-stage breast cancer. Cancer 2008; 113: 2565-74.

67. Foulkes WD, Chappuis PO, Wong N, et al. Primary node negative breast cancer in BRCA1 mutation carriers has a poor outcome. Ann Oncol 2000; 11: 307-13.

68. Nilsson MP, Hartman L, Idvall I, Kristoffersson U, Johannsson OT, Loman N. Long-term prognosis of early-onset breast cancer in a population-based cohort with a known BRCA1/2 mutation status. Breast Cancer Res Treat 2014; 144: 133-42.

69. Nicoletto MO, Donach M, De Nicolo A, Artioli G, Banna G, Monfardini S. BRCA-1 and BRCA-2 mutations as prognostic factors in clinical practice and genetic counselling. Cancer Treat Rev 2001; 27: 295-304.

70. El-Tamer M, Russo D, Troxel A, et al. Survival and recurrence after breast cancer in BRCA1/2 mutation carriers. Ann Surg Oncol 2004; 11: 157-64.

71. Albano WA, Recabaren JA, Lynch HT, et al. Natural history of hereditary cancer of the breast and colon. Cancer 1982; 50: 360-3.

72. Porter DE, Cohen BB, Wallace MR, et al. Breast cancer incidence, penetrance and survival in probable carriers of $B R C A 1$ gene mutation in families linked to BRCA1 on chromosome 17q12-21. Br J Surg 1994; 81: 1512-5.

73. Rennert G, Bisland-Naggan S, Barnett-Griness O, et al. Clinical outcomes of breast cancer in carriers of BRCA1 and BRCA2 mutations. N Engl J Med 2007; 357: 115-23.

74. Bordeleau L, Panchal S, Goodwin P. Prognosis of BRCA-associated breast cancer: a summary of evidence. Breast Cancer Res Treat 2010; 119: 13-24.

75. Lee EH, Park SK, Park B, et al. Effect of BRCA1/2 mutation on short-term and long-term breast cancer survival: a systematic review and meta-analysis. Breast Cancer Res Treat 2010; 122: 11-25.

76. Xu J, Wang B, Zhang Y, Li R, Wang Y, Zhang S. Clinical implica- tions for BRCA gene mutation in breast cancer. Mol Biol Rep 2012; 39: 3097-102.

77. Lucassen A, Watson E, Eccles D. Evidence based case report: advice about mammography for a young woman with a family history of breast cancer. BMJ 2001; 322: 1040-2.

78. Chappuis PO, Nethercot V, Foulkes WD. Clinico-pathological characteristics of BRCA1- and BRCA2-related breast cancer. Semin Surg Oncol 2000; 18: 287-95.

79. Seynaeve C, Verhoog LC, van de Bosch LM, et al. Ipsilateral breast tumour recurrence in hereditary breast cancer following breastconserving therapy. Eur J Cancer 2004; 40: 1150-8.

80. Haffty BG, Harrold E, Khan AJ, et al. Outcome of conservatively managed early-onset breast cancer by BRCA1/2 status. Lancet 2002; 359: 1471-7.

81. Pathology of familial breast cancer: differences between breast cancers in carriers of BRCA1 or BRCA2 mutations and sporadic cases. Breast Cancer Linkage Consortium. Lancet 1997; 349: 150510.

82. Eisinger F, Jacquemier J, Charpin C, et al. Mutations at BRCA1: the medullary breast carcinoma revisited. Cancer Res 1998; 58: 1588-92.

83. Lakhani SR, Jacquemier J, Sloane JP, et al. Multifactorial analysis of differences between sporadic breast cancers and cancers involving BRCA1 and BRCA2 mutations. J Natl Cancer Inst 1998; 90: 113845.

84. Honrado E, Benítez J, Palacios J. The molecular pathology of hereditary breast cancer: genetic testing and therapeutic implications. Mod Pathol 2005; 18: 1305-20.

85. Lynch BJ, Holden JA, Buys SS, Neuhausen SL, Gaffney DK. Pathobiologic characteristics of hereditary breast cancer. Hum Pathol 1998; 29: 1140-4.

86. Eerola H, Heikkilä P, Tamminen A, Aittomäki K, Blomqvist C, Nevanlinna H. Histopathological features of breast tumours in BRCA1, BRCA2 and mutation-negative breast cancer families. Breast Cancer Res 2005; 7: R93-100.

87. Agnarsson BA, Jonasson JG, Björnsdottir IB, Barkardottir RB, Egilsson V, Sigurdsson H. Inherited BRCA2 mutation associated with high grade breast cancer. Breast Cancer Res Treat 1998; 47: 121-7.

88. Lakhani SR, Van De Vijver MJ, Jacquemier J, et al. The pathology of familial breast cancer: predictive value of immunohistochemical markers estrogen receptor, progesterone receptor, HER-2, and p53 in patients with mutations in BRCA1 and BRCA2. J Clin Oncol 2002; 20: 2310-8.

89. Palacios J, Honrado E, Osorio A, et al. Immunohistochemical characteristics defined by tissue microarray of hereditary breast cancer not attributable to BRCA1 or BRCA2 mutations: differences from breast carcinomas arising in BRCA1 and BRCA2 mutation carriers. Clin Cancer Res 2003; 9(10 Pt 1):3606-14.

90. Foulkes WD, Metcalfe K, Sun P, et al. Estrogen receptor status in BRCA1- and BRCA2-related breast cancer: the influence of age, grade, and histological type. Clin Cancer Res 2004; 10: 2029-34.

91. Osin PP, Lakhani SR. The pathology of familial breast cancer: immunohistochemistry and molecular analysis. Breast Cancer Res 1999; 1: 36-40.

92. Eisinger F, Jacquemier J, Charafe-Jauffret E, Rio MC, Birnbaum D, Sobol H. More about: multifactorial analysis of differences between sporadic breast cancers and cancers involving BRCA1 and BRCA2 mutations. J Natl Cancer Inst 1999; 91: 1421-2. 
93. Armes JE, Trute L, White D, et al. Distinct molecular pathogeneses of early-onset breast cancers in BRCA1 and BRCA2 mutation carriers: a population-based study. Cancer Res 1999; 59: 2011-7.

94. Grushko TA, Blackwood MA, Schumm PL, et al. Molecular-cytogenetic analysis of HER-2/neu gene in BRCA1-associated breast cancers. Cancer Res 2002; 62: 1481-8.

95. Foulkes WD, Smith IE, Reis-Filho JS. Triple-negative breast cancer. N Engl J Med 2010; 363: 1938-48.

96. Mavaddat N, Barrowdale D, Andrulis IL, et al. Pathology of breast and ovarian cancers among $B R C A 1$ and $B R C A 2$ mutation carriers: results from the Consortium of Investigators of Modifiers of BRCA1/2 (CIMBA). Cancer Epidemiol Biomarkers Prev 2012; 21: $134-47$.

97. Atchley DP, Albarracin CT, Lopez A, et al. Clinical and pathologic characteristics of patients with $B R C A$-positive and BRCA-negative breast cancer. J Clin Oncol 2008; 26: 4282-8.

98. Sharma P, Klemp JR, Kimler BF, et al. Germline BRCA mutation evaluation in a prospective triple-negative breast cancer registry: implications for hereditary breast and/or ovarian cancer syndrome testing. Breast Cancer Res Treat 2014; 145: 707-14.

99. Noh JM, Han BK, Choi DH, et al. Association between BRCA mutation status, pathological findings, and magnetic resonance imaging features in patients with breast cancer at risk for the mutation. J Breast Cancer 2013; 16: 308-14.

100. Claus EB, Petruzella S, Matloff E, Carter D. Prevalence of BRCA1 and BRCA2 mutations in women diagnosed with ductal carcinoma in situ. JAMA 2005; 293: 964-9.

101. Hoogerbrugge N, Bult P, de Widt-Levert LM, et al. High prevalence of premalignant lesions in prophylactically removed breasts from women at hereditary risk for breast cancer. J Clin Oncol 2003; 21: 41-5.

102. Kauff ND, Brogi E, Scheuer L, et al. Epithelial lesions in prophylactic mastectomy specimens from women with BRCA mutations. Cancer 2003; 97: 1601-8.

103. Adem C, Reynolds C, Soderberg CL, et al. Pathologic characteristics of breast parenchyma in patients with hereditary breast carcinoma, including $B R C A 1$ and $B R C A 2$ mutation carriers. Cancer 2003; 97: 1-11. 